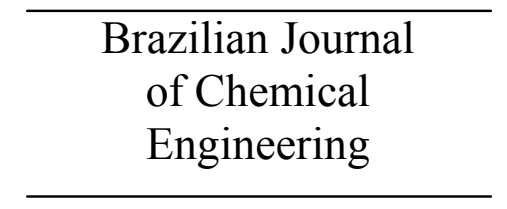

ISSN 0104-6632

Printed in Brazil

www.abeq.org.br/bjche

Vol. 26, No. 04, pp. 635 - 640, October - December, 2009

\title{
RECOVERY OF $p$-TBC FROM A BUTADIENE WASHING STREAM IN A PILOT PLANT
}

\author{
C. F. Lóss ${ }^{1}$, E. B. Azevedo ${ }^{2 *}$ and M. Dezotti ${ }^{3}$ \\ ${ }^{1}$ Petrochemical Complex of Rio de Janeiro, Technology Management, Petróleo Brasileiro S.A., Rio de Janeiro - RJ, Brazil. \\ ${ }^{2}$ Molecular Chemistry and Physics Department, Instituto de Química de São Carlos, Universidade de São Paulo, \\ Phone: + (55) (16) 3373-6692, Telefax: + (55) (16)3373-9975, Av. Trabalhador São-Carlense 400, Centro, \\ Zip Code: 13560-970, P.O. Box: 780, São Carlos - SP, Brazil. \\ E-mail: bessa@iqsc.usp.br \\ ${ }^{3}$ Water Pollution Control Lab, Programa de Engenharia Química / COPPE, \\ Universidade Federal do Rio de Janeiro, Rio de Janeiro - RJ, Brasil.
}

(Submitted: November 25, 2008 ; Revised: May 22, 2009 ; Accepted: May 26, 2009)

\begin{abstract}
Results obtained in a pilot-scale unit designed for COD removal and $p$-TBC (p-tert-butylcatechol) recovery from a butadiene washing stream $\left(\mathrm{pH} 14,200,000 \mathrm{mg} \mathrm{COD} \mathrm{L}^{-1}\right.$, highly toxic) at a petrochemical industry are presented. By adding $\mathrm{H}_{3} \mathrm{PO}_{4}$, phase separation is achieved and $p$-TBC is successfully recovered ( $88 \mathrm{~g} \mathrm{~L}^{-1}$ of washing stream). Information (time for phase separation and organic phase characterization) was gathered for designing a future industrial unit. The estimated heat generation rate was $990 \mathrm{~kJ} \mathrm{~min}{ }^{-1}$ and 15 min were enough to promote phase separation for a liquid column of approximately $1.15 \mathrm{~m}$.
\end{abstract}

Keywords: Butadiene; $p$-TBC; Pilot plant; Industrial effluent.

\section{INTRODUCTION}

Butadiene is an important raw material within the petrochemical industry. It is used for producing polymers, copolymers, resins, and chemical intermediates. Unfortunately, its high reactivity may lead to undesirable reactions during manufacturing, storage, handling, distribution, and use, with butadiene peroxide formation and its own polymerization posing significant safety and health hazards.

To prevent those reactions from happening, butadiene is sold containing 120 to $150 \mathrm{mg} \mathrm{kg}^{-1}$ of $p$ TBC (p-tert-butylcatechol), a polymerization inhibitor. However, several applications require $p$ $\mathrm{TBC}$ to be removed prior to butadiene use.

This work was performed at Petroflex Company, the largest synthetic rubber producer in Latin America, where $p$-TBC is removed from butadiene by washing it with a $15 \% \mathrm{w} / \mathrm{w}$ sodium hydroxide solution, although $p$-TBC could also be removed by activated alumina adsorption (Rivero et al., 2003). This washing generates a highly toxic stream due to its high $\mathrm{pH}$ (around 14) and high $p$-TBC content (Reis et al., 2007), impairing the existing Industrial Wastewater Treatment Plant (IWTP) performance.

Phenolic compounds, like $p$-TBC, are valuable enough for drawing attention to procedures designed to separate and recover them from industrial streams (Venkateswaran and Palanivelu, 2006). Among them, several deal with solubilization with sodium hydroxide (separation) and further acidification (recovery). This approach has been reported by several authors (Han et al., 2001; González-Muñoz et al., 2003; Lazarova and Boyadzhieva, 2004; Ferreira et al., 2005; Jaber et al., 2005; Sawai et al., 2005).

In a previous work (Lóss et al., 2006), it was shown that acidification of Petroflex's butadiene washing stream with phosphoric acid was effective for Chemical Oxygen Demand (COD) removal and $p$-TBC recovery. An initial temperature of $60^{\circ} \mathrm{C}$ and

*To whom correspondence should be addressed 
an acidification down to $\mathrm{pH} 6$ were necessary to avoid crystallization of salts after cooling. Results indicated a COD removal of $97 \%$ and a $p$-TBC recovery of $88 \mathrm{~g} \mathrm{~L}^{-1}$ of washing stream. Since Petroflex generates approximately $15,000 \mathrm{~L}$ of that stream per month, that would mean a monthly recovery of $1,320 \mathrm{~kg}$ of $p$-TBC. Therefore, a significant reduction in the amount of organic matter entering the wastewater treatment unit is achieved.

There are two other important features: (i) the obtained COD removal would mean a reduction of $2,910 \mathrm{~kg}$ of oxygen per month in the wastewater treatment unit aerator, with the corresponding cost savings; and (ii) approximately $3,200 \mathrm{~kg}$ of $\mathrm{CO}_{2}$ per month would cease to be emitted, making the treatment process greener.

Those figures motivated the implementation of a pilot-scale unit at the industrial site. Therefore, the present work reports the results obtained with the pilot-scale unit. The main objectives of the study were to obtain the necessary data to design a recovery process, more specifically three main parameters: heat release, the time necessary for phase separation after completing acidification, and the characterization of the organic phase. Although sulfuric acid has a lower cost compared to phosphoric acid, the latter was used for several reasons: (i) it is safer; (ii) allows better temperature control; (iii) there is no sulphate addition to the stream (avoiding future problems related to water reuse); and (iv) Petroflex already adds polyphosphates to its wastewater streams as a nutrient (cost reduction).

\section{EXPERIMENTAL}

In this work, a butadiene washing stream from a rubber industry (Petroflex, Brazil), generated in the reaction area known as "Soda 23" $(\mathrm{pH}=14, \mathrm{COD}=$ $200,000 \mathrm{mg} \mathrm{O}_{2} \mathrm{~L}^{-1}$ ), was used. Concentrated phosphoric acid $(85 \%$ w/w, Fosbrasil, Brazil) was used as received.

Figure 1 presents a scheme of the pilot plant. It was comprised of a $1 \mathrm{~m}^{3} 304$ stainless steel insulated tank (2:1 semi-elliptic domes) equipped with: an impeller (pneumatic inclined turbine, BOMAX, Agimax F170M-OP007R-400E1, Brazil), a temperature indicator (TI), and a level indicator (LI). "Soda 23" stream was transferred to the tank by a diaphragm pump (WILDEN, P1/PPP/WF/ WF/KWF, USA). Phosphoric acid was added by a dosing pump (OMEL, DMD 1, Brazil).

First, $600 \mathrm{~L}$ of "Soda 23" was fed to the tank followed by turning on agitation. After vapor-heating the tank up to $60^{\circ} \mathrm{C}$, the dosing of phosphoric acid was initiated at a flow rate of $0.8 \mathrm{~L} \mathrm{~min}^{-1}$. After the acid dosing, the agitation was ceased and samples withdrawn from the aqueous phase at regular time intervals.

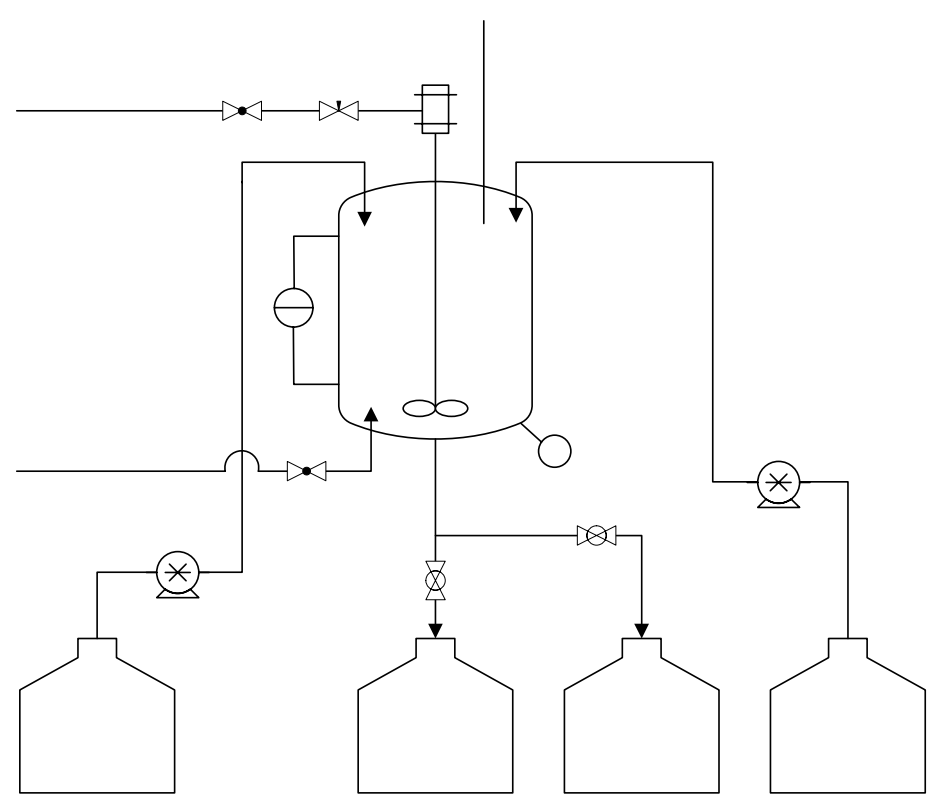

(a)

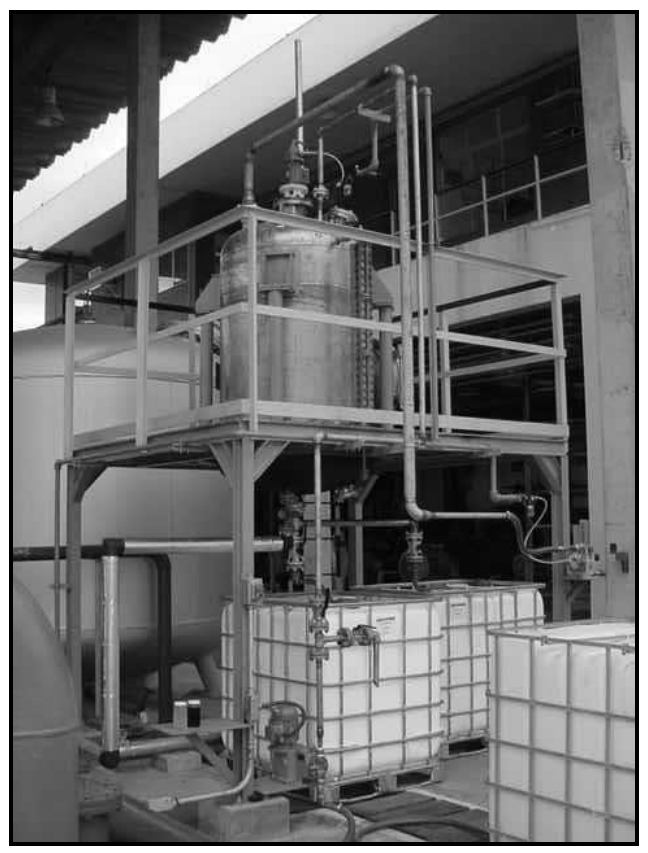

(b)

Figure 1: Pilot plant configuration: (a) schematic diagram and (b) photo of the pilot unit. 
For determining the chemical oxygen demand (COD) of the aqueous phase, the closed-reflux method was used (APHA, 1992).

Chromatographic analyses were performed in order to determine the purity of the phase separated upon acidification. Prior to chromatography, samples were submitted to an adapted liquid-liquid extraction procedure using dichloromethane as the solvent (Czuczwa et al., 1987; Goldberg and Weiner, 1980).

A Shimadzu GC-17A gas chromatograph provided with a DB-5 $(30 \mathrm{~m} \times 0.25 \mathrm{~mm} \times 0.25 \mu \mathrm{m})$ column and a FID detector was employed. The GC temperature was programmed: the injection and detector ports were held at $250^{\circ} \mathrm{C}$ and $280^{\circ} \mathrm{C}$, respectively, and the $\mathrm{GC}$ oven temperature started at $75^{\circ} \mathrm{C}$ and was increased to $250^{\circ} \mathrm{C}$ at $10^{\circ} \mathrm{C} \mathrm{min}{ }^{-1}$. The column head pressure was also programmed: it started at $40 \mathrm{kPa}$ and was increased to $70 \mathrm{kPa}$ at 1.7 $\mathrm{kPa} \min ^{-1}$. The carrier gas $\left(\mathrm{H}_{2}\right)$ was then kept at a flow rate of $0.80 \mathrm{~mL} \mathrm{~min}^{-1}$ and a linear speed of 25 $\mathrm{cm} \mathrm{s}^{-1}$. The extract $(1.0 \mu \mathrm{L})$ was injected in split mode $(1: 30)$.

\section{RESULTS AND DISCUSSION}

The acidification of the wastewater in the pilot plant promoted phase separation. No salt

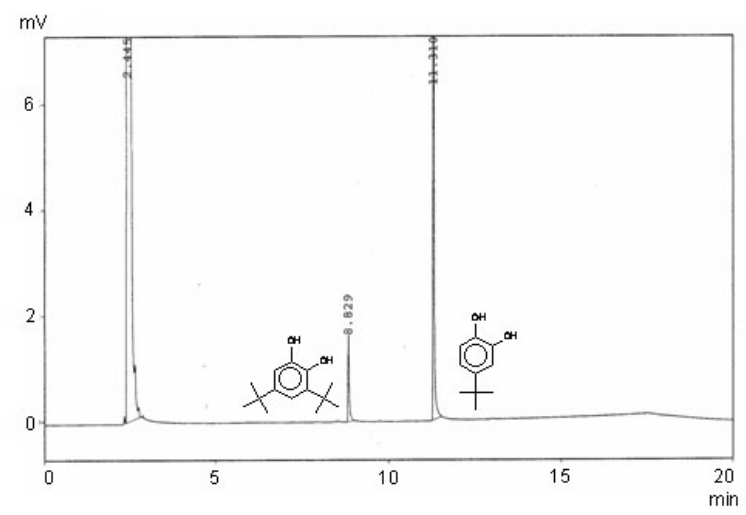

(a) crystallization was observed after cooling down to ambient temperature.

Figure 2 shows two illustrative chromatograms. In Figure 2a, the chromatogram indicates that the "Soda 23 " stream is composed of in fact two compounds: the one having a retention time of $11.310 \mathrm{~min}$ is $p$-TBC itself; the other at $8.829 \mathrm{~min}$ is probably due to a common impurity of commercial $p$-TBC, known as 3,5-di-tert-butylcatechol. However, as depicted by Figure $2 b$, the organic phase separated after acidification is solely composed of $p$-TBC. Therefore, it can be observed that no oxidation products are formed during the acidification and, in addition, that the recovered $p$-TBC is higher in purity than the commercial product.

The heat released during the neutralization of "Soda 23 " increased the system temperature, as the tank was not equipped with a heat exchanger. Figure 3 shows the temperature increase during the experiments performed with a flow rate of $0.8 \mathrm{~L} \mathrm{~min}^{-1}$.

As can be observed in Figure 3, temperature rises linearly up to approximately $96^{\circ} \mathrm{C}-1^{\text {st }}$ stage of the process - and then tends to stabilize $-2^{\text {nd }}$ stage of the process.

During the first stage, the temperature rise is proportional to the mass of acid added to the system, as depicted also in Figure 3. The temperature increase rate was calculated as being $0.4 \mathrm{~K} \mathrm{~kg}^{-1}$ of $\mathrm{H}_{3} \mathrm{PO}_{4}$.

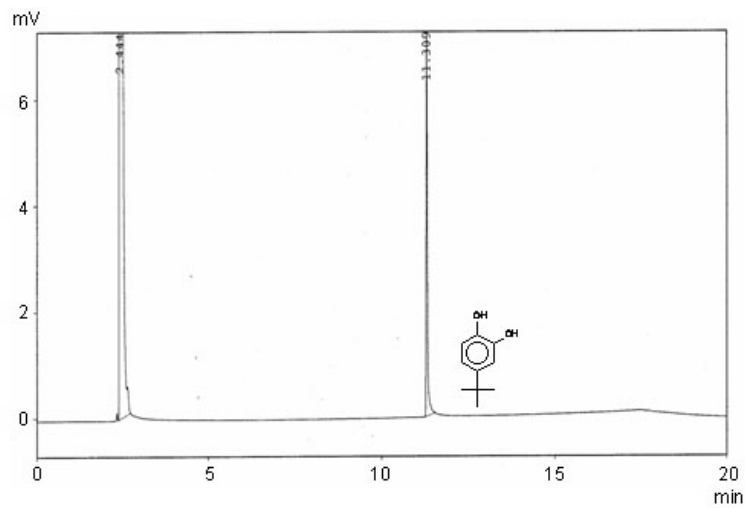

(b)

Figure 2: Chromatogram of (a) Soda 23 and (b) organic layer after acidification.

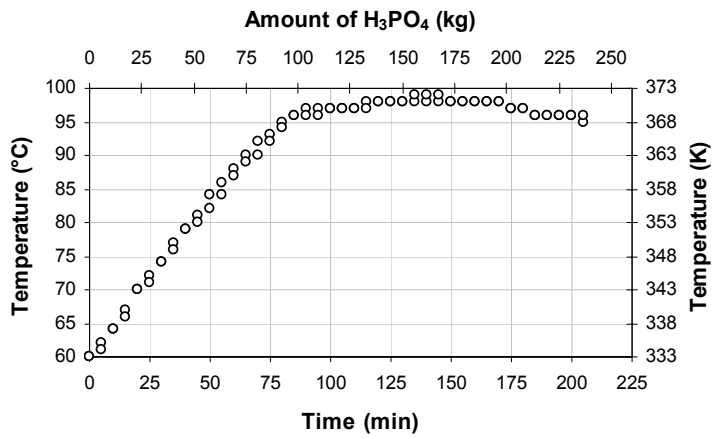

Figure 3: Temperature increase versus time and mass of acid added during Soda 23 acidification with $\mathrm{H}_{3} \mathrm{PO}_{4}$ at an acid flow rate of $0.8 \mathrm{~L} \mathrm{~min}^{-1}$. 
The temperature rise during the first stage is due to the heat released by the neutralization of sodium hydroxide, whose initial concentration is approximately $4.35 \mathrm{~mol} \mathrm{~L}^{-1}$. Soda reacts with phosphoric acid up to a concentration less than $1.0 \mathrm{~mol} \mathrm{L^{-1 }}$ without any noticeable $\mathrm{pH}$ modification, and it is almost completely neutralized when the $\mathrm{pH}$ reaches 13 . Subsequent additions of acid significantly modify the medium $\mathrm{pH}$ and the concentrations of anions $\left(\mathrm{PO}_{4}{ }^{3-}\right.$, $\mathrm{HPO}_{4}{ }^{2-}$, and $\mathrm{H}_{2} \mathrm{PO}_{4}^{-}$) and of phosphoric acid itself. Nevertheless, those reactions are not exothermic $\left(2^{\text {nd }}\right.$ stage of the process).

The theoretical mass of acid needed to acidify $600 \mathrm{~L}$ of wastewater to $\mathrm{pH} 13$ is $88 \mathrm{~kg}$. During the tests, the temperature stabilized when $100 \mathrm{~kg}$ of acid were added. Considering that an error of $1 \%$ in the acid flow rate represents approximately $11.5 \mathrm{~kg}$ during an addition period of $80 \mathrm{~min}$ (average time for the stabilization of the temperature), the real and theoretical acid consumption are close.

If a heat exchanger is to be designed for the system, it is necessary to know the heat exchange rate $\left(\mathrm{Q}_{\mathrm{ex}}\right)$ of the process. As the reactor used was operated in a semi-batch mode, then the energy balance takes the form presented in Equation 1, where: $\dot{\mathrm{m}}$ is the feeding flow rate $\left(\mathrm{kg} \mathrm{min}^{-1}\right)$, which is constant; $\mathrm{m}_{0}$ and $\mathrm{m}$ are the initial and the total mass $(\mathrm{kg})$ inside the tank, respectively; $c_{p}$ and $\mathrm{c}_{\mathrm{p}}^{\mathrm{H}_{3} \mathrm{PO}_{4}}$ are the average heat capacity of the liquid inside the tank and that of the phosphoric acid $(\mathrm{kJ}$ $\mathrm{kg}^{-1} \mathrm{~K}^{-1}$ ). respectively; $\mathrm{T}$ and $\mathrm{T}_{\mathrm{f}}$ are the temperatures of the liquid inside the tank and that of the feeding one, respectively; $\Delta \mathrm{H}$ is the reaction enthalpy $(\mathrm{kJ}$ $\left.\mathrm{mol}^{-1}\right) ; \mathrm{r}$ is the reaction specific rate $\left(\mathrm{mol} \mathrm{m}^{-3} \mathrm{~min}^{-1}\right)$; $\mathrm{V}$ is the volume of liquid inside the reactor $\left(\mathrm{m}^{3}\right)$; and $\mathrm{Q}_{1}$ represents the heat losses to the surroundings $(\mathrm{kJ}$ $\min ^{-1}$ ), which can be neglected because the vessel was insulated.

$\mathrm{m} \cdot \mathrm{c}_{\mathrm{p}} \cdot \frac{\mathrm{dT}}{\mathrm{dt}}=\dot{\mathrm{m}} \cdot \mathrm{c}_{\mathrm{p}}^{\mathrm{H}_{3} \mathrm{PO}_{4}} \cdot\left(\mathrm{T}_{\mathrm{f}}-\mathrm{T}\right)+(-\Delta \mathrm{H}) \cdot \mathrm{r} \cdot \mathrm{V}+\mathrm{Q}_{1}$

First, the feeding flow rate can be equaled to the acid mass flow rate, as losses from evaporation can be neglected. As $\rho_{\mathrm{H}_{3} \mathrm{PO}_{4}}=1.685 \mathrm{~kg} \mathrm{~L}^{-1}$ and $\mathrm{Q}_{\mathrm{H}_{3} \mathrm{PO}_{4}}=0.8 \mathrm{~L} \mathrm{~min}^{-1}$, then $\dot{\mathrm{m}}=1.348 \mathrm{~kg} \mathrm{~min}^{-1}$. The total mass inside the tank, at any time, can be calculate by Equation 2, which comes from the total mass balance, $\mathrm{dm} / \mathrm{dt}=\dot{\mathrm{m}}$, and the corresponding integration assuming that $\dot{\mathrm{m}}$ is constant and that $\left.\mathrm{m}\right|_{\mathrm{t}=0}=\mathrm{m}_{0}(600 \mathrm{~kg})$. $\mathrm{m}=\mathrm{m}_{0}+\dot{\mathrm{m}} \cdot \mathrm{t}$

Second, as depicted by Figure 3, the temperature variation during acid addition is constant (a straight line is observed); this is an indication that the specific heat capacity remains approximately unchanged. In order to calculate the specific heat capacity of the initial solution, the following steps were taken, while $\mathrm{c}_{\mathrm{p}} \mathrm{H}_{3} \mathrm{PO}_{4}$ was retrieved from the literature as $1.53 \mathrm{~kJ} \mathrm{~kg}^{-1} \mathrm{~K}^{-1}$ (NIST, 2008):

(a) The specific heat capacities $\left(\mathrm{c}_{\mathrm{p}}\right)$ at $60^{\circ} \mathrm{C}$ for $p$ TBC, sodium hydroxide, and water were retrieved from literature: 0.2703 (Steele et al., 1997), 1.4178 (Cheresources, 2007), and 4.1843 (CRC, 2004) $\mathrm{J} \mathrm{g}^{-1}$ $\mathrm{K}^{-1}$, respectively;

(b) The mass percentages of each component were calculated $(0.0905,0.174$, and 0.736 for $p$-TBC, sodium hydroxide, and water, respectively); and

(c) The solution specific heat capacity was estimated by a previously proposed method (Dimoplon, 1972), as presented by Equation 3 .

$$
\begin{aligned}
\mathrm{c}_{\mathrm{p}}= & 0.0905 \times 0.2703+0.174 \times 1.4178+ \\
& 0.736 \times 4.1843=3.3487 \mathrm{~kJ} \mathrm{~kg}^{-1} \mathrm{~K}^{-1}
\end{aligned}
$$

During the $1^{\text {st }}$ stage of the process, it can be considered that the acid reacts instantaneously with the base present inside the tank, yielding Equation 4, where $\mathrm{M}$ is the molar mass $\left(\mathrm{kg} \mathrm{mol}^{-1}\right)$ of the acid.

$\mathrm{r} \cdot \mathrm{V}=\frac{\dot{\mathrm{m}}}{\mathrm{M}}$

The substitution of Equation 4 into Equation 1 yields Equation 5, which can be integrated considering that $\mathrm{T}=\mathrm{T}_{0}$ at $\mathrm{t}=0$, resulting in Equation 6 .

$$
\begin{aligned}
& \left(\mathrm{m}_{0}+\dot{\mathrm{m}} \cdot \mathrm{t}\right) \cdot \mathrm{c}_{\mathrm{p}} \cdot \frac{\mathrm{dT}}{\mathrm{dt}}= \\
& \dot{\mathrm{m}} \cdot \mathrm{c}_{\mathrm{p}}^{\mathrm{H}_{3} \mathrm{PO}_{4}} \cdot\left(\mathrm{T}_{\mathrm{f}}-\mathrm{T}\right)+(-\Delta \mathrm{H}) \cdot \frac{\dot{\mathrm{m}}}{\mathrm{M}} \\
& \mathrm{T}=\left(\mathrm{T}_{\mathrm{f}}-\frac{\Delta \mathrm{H}}{\mathrm{c}_{\mathrm{p}}^{\mathrm{H}_{3} \mathrm{PO}_{4}} \cdot \mathrm{M}}\right)- \\
& \frac{\left(\mathrm{T}_{\mathrm{f}}-\frac{\Delta \mathrm{H}}{\mathrm{c}_{\mathrm{p}}^{\mathrm{H}_{3} \mathrm{PO}_{4}} \cdot \mathrm{M}}-\mathrm{T}_{0}\right)}{\left(1+\frac{\dot{\mathrm{m}}}{\mathrm{m}_{0}} \cdot \mathrm{t}\right)^{\frac{\mathrm{c}_{\mathrm{H}} \mathrm{H}_{3} \mathrm{PO}_{4}}{\mathrm{c}_{\mathrm{p}}}}}
\end{aligned}
$$


Then, when Equation 6 is adjusted to the $1^{\text {st }}$ stage data of Figure 3 , it is obtained that

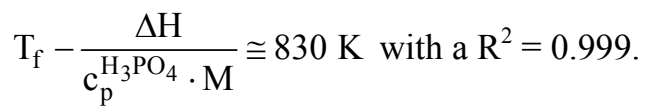

Finally, the required heat exchange rate in order to keep the liquid inside the tank at a constant temperature equal to the initial one, $\mathrm{T}_{0}$, can be calculated directly with Equation 1 replacing $\mathrm{Q}_{1}$ by $\mathrm{Q}_{\mathrm{ex}}$. In this case, $\mathrm{dT} / \mathrm{dt}=0$ and Equation 7 is obtained. Therefore, the calculated $\mathrm{Q}_{\mathrm{ex}}$ is approximately $990 \mathrm{~kJ} \mathrm{~min}^{-1}$.

$\mathrm{Q}_{\mathrm{ex}}=-\dot{\mathrm{m}} \cdot \mathrm{c}_{\mathrm{p}}^{\mathrm{H}_{3} \mathrm{PO}_{4}} \cdot\left(-\mathrm{T}_{0}+\mathrm{T}_{\mathrm{f}}-\frac{\Delta \mathrm{H}}{\mathrm{c}_{\mathrm{p}}^{\mathrm{H}_{3} \mathrm{PO}_{4} \cdot \mathrm{M}}}\right)$

Phase separation was assessed by measuring the residual COD in the aqueous phase. Figure 4 shows the COD variation versus time after agitation was ceased (along with the 95\% confidence limits), resulting from triplicate experiments, for an acid flow rate of $0.8 \mathrm{~L} \mathrm{~min}^{-1}$. Initially, $\mathrm{COD}$ varies greatly but, from $15 \mathrm{~min}$ on, it is practically stabilized, indicating that phase separation was accomplished. This result is quite promising, as a 15min separation time for a liquid column of approximately $1.15 \mathrm{~m}$ can be considered to be fast.

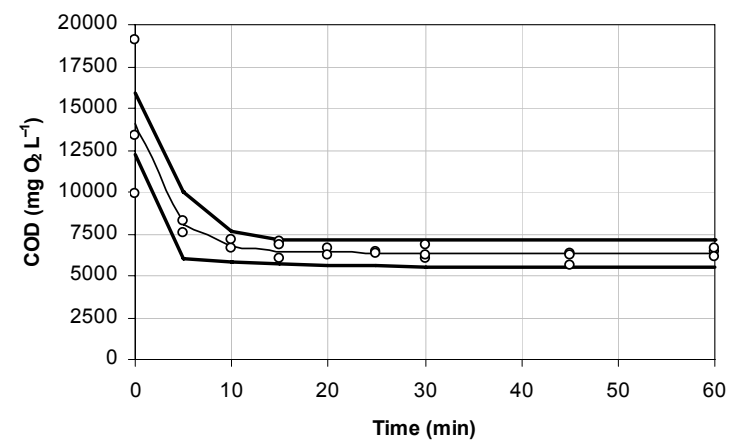

Figure 4: Aqueous phase COD variation versus time after acid addition (phase separation).

\section{CONCLUSION}

The recovery of p-tert-butylcatechol ( $p$-TBC) from a butadiene washing stream at a petrochemical industry was assessed in order to obtain data for design purposes.

The neutralization of the stream with $\mathrm{H}_{3} \mathrm{PO}_{4}$ proved to be an excellent method, due to several reasons: (i) no oxidation products are formed during neutralization; (ii) the recovered $p$-TBC has a higher purity than the commercial $p$-TBC used; and (iii) the time needed for complete phase separation after acid addition is quite short (15 min for a liquid column of $1.15 \mathrm{~m})$.

For designing a future heat exchanger for the recovery process, the heat generation rate was calculated as being $990 \mathrm{~kJ} \mathrm{~min}{ }^{-1}$ during the acid addition step, for an acid flow rate of $0.8 \mathrm{~L} \mathrm{~min}^{-1}$.

It is estimated that a monthly recovery of 1,320 $\mathrm{kg}$ of $p$-TBC can be achieved, decreasing significantly the organic load in the effluent to the biological process used. Cost savings are also significant due to the use of the recovered $p$-TBC and to the reduced oxygen consumption in the aeration tank $(2,910 \mathrm{~kg}$ per month). Finally, it was also estimated that the recovery process would prevent $3,200 \mathrm{~kg}$ of $\mathrm{CO}_{2}$ from being emitted to the atmosphere per month, making the industry operation greener.

\section{ACKNOWLEDGMENTS}

The authors thank Petroflex, CNPq, and FUJB for financial support.

\section{REFERENCES}

APHA-AWWA-WEF, Standard methods for the examination of water and wastewater, section 5220D (1992).

Cheresources. http://www.cheresources.com/estcp. shtml. (Accessed on June, 2007).

CRC Press LLC, CRC Handbook of Chemistry and Physics, Washington DC (2004).

Czuczwa, J., Leuenberger, C., Tremp, J. and Giger, W., Determination of trace levels of phenol and cresols in rain by continuous liquid-liquid extraction and high-performance liquidchromatography, J. Chrom. A, 403, 233 (1987).

Dimoplon, W., Estimating specific-heat of liquid mixtures, Chem. Eng., 79, 64 (1972).

Ferreira, F. C., Peeva, L., Boam, A., Zhang, S. and Livingston, A., Pilot scale application of the Membrane Aromatic Recovery System (MARS) for recovery of phenol from resin production condensates, J. Memb. Sci., 257, 120 (2005).

Goldberg, M. C. and Weiner, E. R., Extraction and concentration of phenolic compounds from water and sediment, Anal. Chim. Acta, 115, 373 (1980).

González-Muñoz, M. J., Luque, S., Álvarez, J. R. and Coca, J., Recovery of phenol from aqueous 
solutions using hollow fiber contactors, J. Memb. Sci., 213, 181 (2003).

Han, S., Ferreira, F. C. and Livingston, A., Membrane aromatic recovery system (MARS) a new membrane process for recovery of phenols from wastewaters, J. Memb. Sci., 188, 219 (2001).

Jaber, A. M. Y., Ali, S. A. and Yahaya, G. O., Studies on phenol permeation through supported liquid membranes containing functionalized polyorganosiloxanes, J. Memb. Sci., 250, 85 (2005).

Lazarova, Z. and Boyadzhieva, S., Treatment of phenol-containing aqueous solution by membranebased solvent extraction in coupled ultrafiltration modules, Chem. Eng. J., 100, 129 (2004).

Lóss, C. F., Azevedo, E. B., Dezotti, M., Treatment of the butadiene washing stream from a synthetic rubber industry and recovery of $p$-TBC, Wat. Sci. Technol., 54, 17 (2006).

NIST. http://webbook.nist.gov/cgi/cbook.cgi?ID= C7664382\&Mask=2\#Thermo-Condensed. (Accessed on November, 2008).

Reis, J. L. R., Dezotti, M. and Sant'Anna Jr., G. L.,
Toxicity evaluation of the process effluent streams of a petrochemical industry, Environ. Technol., 28, 147 (2007).

Rivero, M. J., Ibánez, R. and Ortiz, M. I., Analysis of the elimination process of polymerization inhibitors from styrene by means of adsorption, $\mathrm{J}$. Chem. Technol. Biotechnol., 78, 64 (2003).

Sawai, J., Ito, N., Minami, T. and Kikuchi, M., Separation of low volatile organic compounds, phenol and aniline derivates, from aqueous solution using silicone rubber membrane, J. Memb. Sci., 252, 1 (2005).

Steele, W. V., Chirico, R. D., Knipmeyer, S. E. and Nguyen, A., Vapor pressure, heat capacity, and density along the saturation line, measurements for dimethyl isophthalate, dimethyl carbonate, 1,3,5-triethylbenzene, pentafluorophenol, 4-tertbutylcatechol, $\alpha$-methylstyrene, and N,N $\alpha$-bis(2hydroxyethyl)-ethylenediamine, J. Chem. Eng. Data, 42, 1008 (1997).

Venkateswaran, P. and Palanivelu, K., Recovery of phenol from aqueous solution by supported liquid membrane using vegetable oils as liquid membrane, J. Haz. Mat., 131, 146 (2006). 